\title{
As montanhas se desfarão: sincretismo imagético na apocalíptica judaico-zoroastrista
}

\author{
The mountains should disappear: imagetic syncretism in jewish-zoroastrian \\ apocalypticism
}

Raul Vitor Rodrigues Peixoto *

\begin{abstract}
Resumo
O presente artigo tem por objetivo comparar duas paisagens apocalípticas cujas semelhanças acabam por saltar aos olhos apesar de pertencerem a tradições religiosas distintas. Trata-se do "Aplainamento da Terra" que aparece tanto na apocalíptica judaica quanto na zoroastrista. Até que ponto uma tradição pode ter influenciado a outra? Teríamos aqui por certo um caso de sincretismo imagético? 0 texto judaico de 1 Enoque 67 poderia ser encarado como um portador de tradições escatológicas zoroastristas presentes na Grande Bundahishn Iraniana? Para lidar com estas questões o artigo olha para o tema das Montanhas em fontes poéticas, proféticas e cosmogônicas, tanto zoroastristas como judaicas, a fim de conceber como estes acidentes geográficos eram tratados quando citados. Baseado então na análise destes textos um exercício de compreensão histórica é feito: Por que, para ambas as tradições, as Montanhas devem desaparecer? Enquanto constrói seu diálogo com o estado da arte o artigo não se furta a travar um debate interpretativo no sentido de trazer a leitura das fontes antigas ao seu contexto mais imediato de recepção. Busca-se destarte, evitar o problema da retroalimentação dos textos antigos com concepções anacrônicas.
\end{abstract}

Palavras-chave: judaísmo-helenístico; literatura apocalíptica; sincretismo religioso no mundo antigo.

\begin{abstract}
This article aims to compare two apocalyptic landscapes whose similarities end up jumping in the eyes despite belonging to different religious traditions. It is the "Leveling of the Earth" that appears in both Jewish and Zoroastrian apocalyptic. To what extent has one tradition influenced the other? Would we have here a case of image syncretism? Could the Jewish text of 1 Enoch 67 be regarded as a herald of Zoroastrian eschatological traditions present in the Great Iranian Bundahishn? To deal with these issues the article looks at the theme of the Mountains in poetic, prophetic, and cosmogonic sources, both Zoroastrian and Jewish, in order to conceive how these geographical accidents were treated when quoted. Based on the analysis of these texts, an exercise in historical understanding is made: Why, for both traditions, should the Mountains disappear? Constructing his dialogue with the state of the art, the article does not shy away from waging an interpretive debate in order to bring the reading of the ancient sources to their more immediate context of reception. Thus, we try to avoid the problem of feedbacking anachronistic conceptions on ancient texts.
\end{abstract}

Keywords: hellenistic judaism; apocalyptic literature; religious syncretism in ancient world.

Artigo submetido em 06 de junho de 2018 e aprovado em 28 de abril de 2019.

* Doutor em História pela Universidade de Brasília. Professor no Instituto Federal de Goiás. País de origem: Brasil. E-mail: soliduspetrus@gmail.com 


\section{Introdução}

Judaísmo e Zoroastrismo foram duas tradições religiosas com ampla influência no pensamento cristão-ocidental. Diversos conceitos que encontramos já completamente arraigados em nossa cultura têm origens traçáveis nas duas tradições. Em especial para este artigo, sublinhamos a noção de que o tempo e o espaço como o conhecemos não durarão para sempre, mas terão um fim, não para recomeçar mais um ciclo extremamente igual ao anterior. Este "fim" marcaria o começo de uma era nunca antes vista, ela se desenrolaria num espaço também completamente novo, sob a influência direta do divino. Trata-se da cosmovisão apocalíptica.

Este artigo busca corroborar a hipótese de que o Judaísmo do Segundo Templo, mais especificamente em sua literatura Pseudepigráfica, tenha sido influenciado por tradições apocalipticistas persa-zoroastristas. Estas muito provavelmente ainda não existiriam cristalizadas em forma escrita à época, mas circulavam oralmente, por meio de uma fortíssima tradição deste tipo, capaz, por exemplo, de preservar oralmente os hinos do Avesta ${ }^{1}$ por quase oito séculos até que fossem finalmente postos por escrito no período sassânida.

Os paralelos existentes entre os capítulos 34 da Grande Bundahishn Iraniana $^{2}$ (doravante Bd) e os capítulos 52, 53 e 67 do Livro Etiópico de Enoque

\footnotetext{
${ }^{1} \mathrm{O}$ conjunto de textos mais sagrados do zoroastrismo.

${ }^{2}$ A Bundahishn, do persa-médio "Criação" (MACKENZIE, 1986, p. 109), é uma compilação zoroastrista de cosmogonia, cosmologia e escatologia. Logo no início da obra, é afirmado que o seu conteúdo é zand-āgāhīh, do persa-médio "conhecimento derivado dos Zands" (MACKENZIE, 1986, p. 6), isto é, comentários em persa-médio da tradição avéstica. Isso demonstra a importância dada pelo(s) compilador(es) à legitimação dos escritos como tradição antiga pertencente ao Dēn, nome dado pelos próprios zoroastristas ao amálgama de sua tradição religiosa (MACKENZIE, 1986, p. 26). De acordo com Hultgård, a base dos materiais na Bd já havia sido compilada no final do período sassânida, entretanto a redação final não pode ter acontecido antes do período de invasão islâmica já que o texto final carrega claras alusões à conquista árabe-muçulmana do Irã. Os pesquisadores ocidentais convencionaram que há duas diferentes linhas de compilação da Bd: uma indiana e outra iraniana. A tradição de manuscritos reduzida denota a versão indiana, enquanto nos manuscritos iranianos transmitidos, a tradição é mais expandida - daí se chamar ocasionalmente "Grande Bundahishin Iraniana", não por ser mais valioso, mas simplesmente por uma questão de extensão física. Hultgård faz interessante ressalva no sentido de que esse consenso quanto à nomenclatura da Bd pode causar confusão, sendo importante ressaltar que, apesar de reconhecidas essas duas linhas de transmissão manuscritas, é consenso que ambas são cópias de uma única Bd original e não de duas Bd com gêneses diversas (HULTGÅRD, 1999, p. 42).
} 
(doravante 1En) ${ }^{3}$ não podem ser sinceramente explicados pelo acaso e exigem uma atenção séria que não dispense as evidentes semelhanças a partir de explicações simplistas. Tais paralelos aparecem sequencialmente numa narrativa mítica que chamo de "Ordálio Universal", uma paisagem apocalíptica envolvendo seres angelicais e divinos, montanhas metálicas e um rio de metal incandescente. Tanto na narrativa zoroastrista quanto na judaica, toda a humanidade e até seres sobrenaturais deverão passar por esse rio, e por ele serão sentenciados como ímpios ou justos.

O sincretismo dessas imagens poéticas utilizadas para a descrição de eventos apocalípticos se deu com um alcance muito significativo, principalmente se pensarmos em padrões de Mundo Antigo. Uma imagética compartilhada por culturas que se encontravam, desde as estepes da atual Rússia, caso dos zoroastristas, até a Palestina, judaica tem amplidão considerável e certamente merece atenção.

Ao compararmos os textos percebemos que sua característica mais comum é a presença de montanhas que em dado momento da cena começam a se derreter. $\mathbf{E}$ por isso que decidimos prosseguir a análise por este caminho cotejando as diversas fontes históricas nas quais a imagem de montanhas recorre primeiramente para as zoroastristas e posteriormente as judaicas.

Analisemos a questão das montanhas no zoroastrismo e no judaísmo, haja vista a importância desses acidentes geográficos para a imagética apocalíptica em questão. Mais especificamente, trata-se da imagem do "Aplainamento da Terra", recorrente no A.T. assim como na Bd.

\footnotetext{
${ }^{3}$ A datação de 1 En é um assunto que já passou por vários estágios de discussão com várias sugestões que variaram em cerca de quatro séculos. $O$ assunto é complexo e envolve alguns problemas básicos como a não sobrevivência de manuscritos aramaicos ou hebraicos para a parte ge'ez (etiópica) do livro, ausência de alusões históricas claras, dentre outros. Por ser um texto com importância determinante para a história primeva do cristianismo e para a caracterização do judaísmo do Segundo Templo, 1En continua bastante disputado. Os capítulos citados neste artigo dizem respeito a uma subseção de 1En conhecida como "Livro das Parábolas". Pierl uigi Piovanelli acredita que o Livro das Parábolas, juntamente com a Bíblia - canônicos e apócrifos -, tenham sido traduzidos do grego para o ge'ez em torno de 340 e 525 d.C. - mais provavelmente entre 340 e 400 . Não há condições de saber se o grego fora copiado do aramaico ou do hebraico, o que para o autor é um dos maiores obstáculos para quem estuda as Parábolas (PIOVANELLI, 2007, p. 235). Há intenso debate sobre a datação das Parábolas variando entre séc. I a.C. e I d.C. e mais sobre pode ser visto em Enoch and the Messiah Son of Man: Revisiting the Book of Parables. (BOCCACCINI, 2007).
} 
Sabe-se que o cânon do A.T. não é uma unidade e que foi escrito ao longo de vários séculos, sendo organizado posteriormente. Ele é aqui utilizado, dessa forma, porque, no caso, o que interessa é a receptividade desses textos no período do Segundo Templo. Como a parte de 1 En que está sendo analisada foi provavelmente redigida nesse período, a imagética das montanhas é composta pela influência dos livros veterotestamentários que já estavam disponíveis à época. Segundo James Charleswoth, apesar de o cânon veterostestamentário ter sido fechado em Jâmina, no ano de 90 d.C., muito anteriormente, já no século II a.C., os judeus tinham firmado uma forte tendência daqueles seriam seus livros mais importantes e influentes (CHARLESWORTH, 2013, p. XXIII). A meu ver, isso legitima o A.T. como uma unidade de pesquisa imagética para determinar com mais clareza o que as montanhas poderiam significar para os judeus que escreveram o que veio a ser conhecido como Livro Etiópico de Enoque e, assim, chegarmos a alguma resposta para as seguintes perguntas quanto às montanhas da Bundahishn: apenas uma coincidência de utilização de imagens que tem um outro sentido? Ou de fato não só a imagem é a mesma, mas também o sentido imagético?

\section{As montanhas se desfarão - as fontes iranianas}

O pesquisador da Universidade de Minessota, Bruce Lincoln4, teve sua atenção chamada para a questão do aplainamento da Terra por meio do capítulo 34 da Bd. A partir daí ele atestou que:

The image of the leveling of mountains, while widespread in other traditions, occurs only these three times in texts relating to Iranian religion: the Bundahišin, Plutarch's lsis and Osiris, and the Oracles of Hystaspes as preserved in Lactantius's Divine Institutions. As we have seen, for all that these sources share the common image, they treat it quite differently. (LINCOLN, 1983, p. 137).

Faz-se necessário, então, por entendimento de que o estado da arte desse tema seja escasso, apresentar um resumo das pesquisas de Lincoln acerca deste que é o assunto central desta parte. Devemos compreender por que motivos Lincoln considera que o aplainamento da Terra tenha sentidos diferentes nas

\footnotetext{
${ }^{4}$ Por se tratar de uma crítica direta aos argumentos apresentados pelo autor, optou-se por manter o texto no original inglês.
} 
fontes zoroastristas que aparece (a saber: Bd, Ísis e Osíris, Oráculos de Hystaspes e Zand i Wahman Yasht5).

O notável nas pesquisas de Lincoln é que ele chegou à conclusão de que o aplainamento da Terra e a fundição das montanhas que ocorrem na Bd 34 são estranhos à tradição avéstica mais antiga: "Yasna' 1.14, 2.14. Yasna 71.10 mentions a sacrifice to all mountains, within the context of a sacrifice to all good and holy creations made by Ahura Mazdā7 (LINCOLN, 1983, p. 137)”. De fato, o Yasht 19 contém em seus oito primeiros versos uma detalhada lista de montanhas, citando inclusive o número exato de montanhas que obra afirma existir. Porém o v.8 é impactante no que diz respeito à dubiedade com que as montanhas são tratadas nas fontes zoroastristas (Yasht 19:8): "Para estas direções as montanhas estendem seus ramos, elas provem comida para o sacerdote, o guerreiro e o agricultor, portador de prosperidade, em todas estas direções”. Trata-se de um texto muito esclarecedor e até espanta o fato de Lincoln não o ter transcrito em seu artigo. O autor sumariza o papel das montanhas na tradição Gática: assim como uma série de outras paisagens naturais, são consideradas como boa criação de Ahura Mazdā. Há ainda o registro grego feito por Heródoto acerca das práticas ritualísticas persas apresentando-os como povo que possuía grande veneração pelos picos das montanhas, os considerando locais sagrados e constantemente sacrificando nestes (HERÓDOTO, 1911, p. 131). ${ }^{8}$

\footnotetext{
${ }^{5}$ Apocalipse zoroastrista escrito em persa-médio considerado um dos mais importantes por apresentar a narrativa da árvore com galhos metálicos, esta simbolizando uma sequência de impérios mundiais (uma versão mais antiga no cap.1 e um desenvolvimento posterior no cap. 3). A imagem desta árvore de galhos metálicos e sua significância levantaram inúmeras discussões nas últimas décadas por seus paralelos evidentes com Dn 2:27-45 (SUNDERMANN, 1988).

${ }^{6}$ Nome dado aos hinos que hoje são identificados como o material de maior antiguidade no Avesta. Os hinos podem aparecer também com seu nome avéstico "Gāthā" pl . "'Gāthās".

${ }^{7}$ Avéstico Ahura Mazdā. Em certos textos, a divindade pode aparecer simplesmente como Mazdā, ou até Mazdā Ahura. Estes dois epítetos que formam o nome da divindade referem-se, segundo Skjærvø, às suas funções, porém dada a antiguidade das palavras o autor prefere não fazer uma tradução das mesmas (SKJ/ERVØ 2006, p. 16). Já Boyce apresenta uma possível tradução para os epíte tos: Senhor da Sabedoria (BOYCE, 1990, p. 9). Hintze traduz Mazdā como "O que põe todas as coisas em sua mente" (HINTZE, 2014). No persa-médio, aconteceu uma monossilabização da parte inicial do nome que resultou em Ohrmazd; trata-se, porém, da mesma divindade no entendimento dos zoroastristas e da maioria dos estudiosos (isto é, não há discussões semelhantes à questão Elōhīym Javé).

8 "As to the usages of the Persians, I know them to be these. It is not their custom to make and set up statues and temples and altars, but those who make such they deem foolish, as I suppose, because they never believed the gods, as do the Greeks, to be in the likeness of men; but they call the whole circle of heaven Zeus, and to him they offer sacrifice on the highest peaks of the mountains; they sacrifice also to the sun and moon and earth and fire and water and winds."
} 
Acerca desse desvio de cosmovisão que ocorre entre os textos Gáticos e a Bd, Lincoln afirma que muitos estudiosos já tentaram explicações que, para ele, não foram satisfatórias. Para o autor, a questão pode ser dirimida apenas com uma análise mais profunda do contexto geral do capítulo 34 da Bd. Esse trecho é de grande significância para o estudo da literatura apocalíptica iraniana como um todo, pois, em uma única unidade narrativa, concentram-se assuntos como ressurreição dos mortos, recebimento da imortalidade, destruição e fuga de demônios, julgamento final e, como um fechamento de todos esses eventos, chegase ao nivelamento final da Terra. De acordo com Lincoln, "The level plain, devoid of mountainous disruptions, emerges as the ultimate sign of the cosmic Renovation (Frashagird) (LINCOLN, 1983, p. 137)”.

Vejamos o tão comentado trecho da Bd 34:

16. Durante a renovação (no fim dos tempos), aqueles homens justos, dos quais está escrito, estão vivendo, quinze homens e quinze jovens mulheres, aparecerão para ajudar os Soshyans ${ }^{9}$. [...] 18. Então, o Fogo ${ }^{10}$ e o yazad ${ }^{11}$ Erman derreterão o metal que está nas montanhas e colinas, e (o metal) estará na terra como um rio. $19 \mathrm{E}$ então eles transportarão todos os homens através desse metal derretido, e os purificarão; e os que são justos, a eles parecerá como se eles estivessem andando em leite morno; e àquele que é perverso, então será como se da mesma maneira que no mundo material estivesse andando em metal derretido 20. Então, por meio deste que é o maior amor, todos os homens verão uns aos outros; pai e filho e irmão e todos os amigos; um homem perguntará a outro homem: "Todos esses anos, onde tu estiveste? O julgamento de tua alma qual foi? Reto ou ímpio?” 21. Primeiro, a alma verá o corpo, e irá perguntar; em resposta será dito, os homens serão de uma mesma voz unidos, e irão entoar louvores a Ohrmazd e aos Amahrspand ${ }^{12}$. [...] 33. Isto também é dito: "Esta Terra ficará sem coroas e sem fundos, nivelada; não haverá montanhas nem picos, cavidades, terras altas ou terras baixas" (KASSOCK, 2013, p. 399, 402, tradução nossa).13

\footnotetext{
${ }^{9}$ Do persa-médio "salvador" (MACKENZIE, 1986, p. 75). Figuras escatológicas no zoroastrismo relacionadas a funções sotereológicas.

${ }^{10} \mathrm{O}$ "Fogo" é considerado um ser na mitologia zoroastrista, isto é, uma hipóstase.

${ }^{11}$ Um ser digno de adoração. Conceito complexo na Monolatria zoroastrista. Para mais ver: HINTZE, Monotheism: The Zoroastrian Way, Journal of the Royal Asiatic Society, 2014.

${ }^{12}$ Os "Sete Espíritos" de Ahura Mazdā (Persa-médio=Ohrmazd). Para mais ver o mesmo artigo citado na nota anterior.

${ }^{13}$ 16. Andar èn frašagird kardārīh, awēšāan mardān ì ahlāwān, ì nibišt kū zīndag hēnd, pānzdah mard ud pānzdah kanīg, ō ayārīh i Sōšyāns bē rasēnd. [..] 18. Pas, ātaxš ud Ėrmān yazd; ayōxšust ì andar kōfān ud garān widāzēnd, ud pad ēn zamīg rōd homānāg ēstēd. 19. Ud pas harwisp mardōm andar ān ayōxšust ì widāxtag bē widārēnd, ud pāk bē kunēnd; ud kē ahlāw, èg-eš ōwōn sahēd, čiyōn ka andar šîr i garm hamē rawēd; ud kē druwand, èg-eš ham ēwēnag sahēd kū pad gētīy andar ayōxšust ì widāxtag hamē rawēd. (20) Pas, pad ān ì mahist dōšāram, harwisp mardōm ō ham rasēnd; pid ud pus ud brād ud hamāg dōst; mard az mard pursēnd kū: "Ān and sāl, kū būd hād? ut pad ruwān dādestān čè būd? ahlāw būd hē ayāb druwand?" 21. Nazdist, ruwān tan wēnēd, uš pursēd; pad ān guft passox, mardōm āgenēn ham-wāng bawēnd, ud buland stāyišnīh ō Ohrmazd ud Amahrspandān barēnd. [..] 33. Ën-iz gōwēd kū: "Ën zamīg anabēsar ud a-nišēéb ud hāmōn bē bawēd; ud kōf ud čagād, ud gabr, ud ul dārišn ud frōd dārišn nē bawēd. (KASSOCK, 2013, p. 399 e 402)". Tradução própria, feita a partir da transliteração e transcrição de Zeke Kassock, devidamente autorizada pelo mesmo.
} 
É importante perceber que a narrativa zoroastrista faz do nivelamento das montanhas e colinas o meio pelo qual o julgamento ordálico é feito, pois é de seu derretimento que vem o metal incandescente necessário para realizar o ritual. Nesta junção entre o aplainamento da Terra e o julgamento ordálico pelo metal incandescente, os motivos da Bd são mixados a outros presentes na tradição Gática Avéstica, como pode ser visto em trechos tais quais Yasna 30:7-8; 32:7 e 51:9.

Num outro texto, no qual se acredita estar colocada a tradição zoroástrica, a obra de Plutarco (1911) conhecida como "Ísis e Osíris", encontramos a passagem que segue no capítulo 47:

But a destined time shall come when it is decreed that Areimanius, engaged in bringing on pestilence and famine, shall by these be utterly annihilated and shall disappear; and then shall the earth become a level plain, and there shall be one manner of life and one form of government for a blessed people who shall all speak one tongue. (PLUTARCO, 1911).

Ao analisar tal trecho, Lincoln atesta o seguinte ${ }^{14}$ :

Of foremost interest to us, however, is the fact that the leveling of the earth is directly related to the emergent unity of all mankind. For at the time of Ahriman's fall, those distinctions which serve to separate people one from another interfering political systems and differing languagesdisappear, and "one life" (ena bion) comes into being for all humanity. (LINCOLN, 1983, p. 140).

Lincoln entende as montanhas como um simbolismo das diferentes classes sociais que separam os homens. Entretanto, penso que essa conclusão de Lincoln esteja errada. Tanto para persas-zoroastristas, quanto para judeus as montanhas podem sim separar povos, mas não são símbolo de separação entre classes sociais.

Entre os judeus, as montanhas podem ser instrumentos para que os homens se diferenciem, porém, não como classes sociais, mas como povos distintos. Podemos ver, no Tanakh, trechos que caracterizam cidades que estão em topos de montanhas como suscetíveis à arrogância e à pretensão'15. Porém essa imagem é

\footnotetext{
${ }^{14}$ Como há crítica ao argumento central de Bruce Lincoln, decidiu-se por não fazer a versão portuguesa dos trechos arrolados. 0 artigo é considerado seminal e ainda é citado por bibliografia da presente década. Não foram encontrados, em língua inglesa e francesa, artigo, tese ou livro publicado que trate do assunto específico das montanhas além do de Lincoln.

${ }^{15}$ Ob 1:3-4. "A arrogância de teu coração te enganou, a ti que moras nas fendas do rochedo, tendo as Alturas como habitação, que dizes em teu coração: 'quem me fará descer à terra?' Se voares como uma águia e se colocares entre as estrelas o teu ninho, de lá eu te farei descer oráculo de Javé" (Versão King James).
} 
muito ligada à coletividade pecadora e/ou inimiga do povo judeu, ficando difícil fechar um argumento que veja as montanhas como diferenciadoras de classes sociais entre os judeus.

Lincoln defende, entretanto, que seu argumento conta com uma prova filológica de que as montanhas na Bd 34 sejam um simbolismo social. Ele apela para um sentido figurativo para o termo persa-médio an-abēsar:

That in the image of the leveling of mountains we are to understand the disappearance of social class is made clear by a key term in the Greater Bundahishn 34.33, the verse with which we began; there it is stated that when the earth becomes flat, it will be "without a crown" (anabesar), a term which simultaneously refers to the peak of geological formations and the peak of society, kingly power. What is more, the description of social classes along lines of a vertical hierarchy is extremely ancient in Iran, being attested already in the Gathic Avesta, as in Yasna 29.3, where the injustice of such distinctions is soundly denounced. (LINCOLN, 1983, p. 143).

É nesta parte de seu argumento que, penso eu, Lincoln se perde numa armadilha exegética. Identifica-se dois problemas: o primeiro diz respeito à interpretação da Yasna 29:3 e o segundo, à análise exegética do termo persa-médio "an-abēsar".

O trecho da Yasna 29:3, conforme citado por Lincoln, é o que segue: "None of them can comprehend [how] those who are lofty proceed against the lowly" (LINCOLN, 1983, p. 143). Porém, West dá uma tradução um tanto quanto diferente:

3. To him Right, no breacher of unity, no enemy of the cow, will answer: 'Of those things there is no knowing. He by whom the upright invigorate the weak is the mightiest of beings; to his calls I will respond, my ear reaches no further: 4.'the Mindful One, the most heedful of initiatives, both those taken in the past by Daevas and mortals, and those that may be taken hereafter. He is the lord that judges; it will be as He will.' (WEST, 2010, p. 622).

O v. 4 foi adicionado propositadamente para prover a perícope usada por Lincoln de contexto. Para afirmarmos que o hino trata das lutas entre classes sociais, teríamos de ter um conflito entre um guerreiro e um clérigo ou entre um 
pastor e um guerreiro, mas o que encontramos, ao longo do capítulo, segundo West, é deveras diverso do que afirma Lincoln:

Esta excepcional composição está preocupada com as tribulações dos donos de gados na sociedade zoroastrista. Ele trata desse tópico em diversos outros poemas $(31: 9-10 ; 32: 8-14 ; 33: 4 ; 44: 6,20 ; 51: 14)$, onde parece que o gado é repetidamente roubado de seus pastos e condenado ao sacrifício. Aqui ele imagina os sentimentos da própria vaca e enquadraos num apelo aos poderes superiores, o que os leva a um preocupado debate entre si. (WEST, 2010, p. 612).

Pelas conclusões de West, tradutor de avéstico e especialista em religiosidade antiga, está claro que o Gāthā em questão está tratando do recorrente conflito entre a sociedade pastoril - da qual Zarathustra fazia parte - e seus inimigos, os ladrões de gado, que pertenciam, ao que se saber, a outras tribos nômades. Além disso, o diálogo entre o espírito da vaca, animal importantíssimo entre os zoroastristas, e o seu Senhor criador, aponta para a intenção inicial do hino que é a de tratar do problema do roubo e sacrifício do animal. Essa interpretação, mais ligada ao problema material da perda do gado e ao mesmo tempo ao problema ritualístico do sacrifício do gado bovino, está em maior consonância com as pesquisas mais recentes ${ }^{16}$. $\mathrm{O}$ uso feito por Lincoln de uma tradução ultrapassada da Yasna 29:3, bem como do verso isolado, é deveras problemático em minha opinião.

Vamos agora ao segundo problema: à análise do termo Persa Médio anabēsar. Segundo MacKenzie, “an” é prefixo pré-vocálico privativo e "abēsar” aparece como tendo o único significado de “coroa” (MACKENZIE, 1986, p. 3). Isso mostra que a questão deve ser dirimida hermeneuticamente, posto que a via

\footnotetext{
${ }^{16}$ Essa concepção parece estar em consonância com o que pode se chamar de "virada-ritualística" nos estudos masdeístas dos últimos quinze anos. Carlo G. Cereti e Prods O. Skjærvø são, em minha opinião, expoentes dessa corrente interpretativa que entende os textos gáticos, ou seja, os textos mais próximos do mundo indo-iraniano, como tendo significância estritamente ritualística. Isto significa dizer, por exemplo, que a tríade zoroastrista "bons pensamentos, boas palavras, boas ações" se referia à obrigação do poeta-sacrificante na condução perfeita do ritual da Yasna, isto é, com sagacidade mental, mantenimento da métrica gática e com exatidão performática. Cereti e Skjærvø não negam o posterior desenvolvimento de uma interpretação ética da tríade zoroastrista, entretanto, sua leitura aproxima os Gāthās da literatura rigvédica e, consequentemente, do mundo indo-iraniano, de certa forma, diminuindo a imagem "reformista" do Zoroastrismo. Skjærvø (2007) expõe abertamente essas concepções em Videvidat: its Ritual Mythical Significance (The Age of Partians) enquanto Cereti (2015) em Myths, Legends, Eschatologies (Blackwell Companion to Zoroastrinism). A aproximação dos autores tem características muito sólidas, contando com argumentos tanto filológicos quanto do que era possível em questões de abstração naquele contexto. Entretanto, devemos ser cautelosos quanto à homegenizações com a tradição rigvédica. A proibição da adoração aos deuas (Persa-médio= dews) nos Gāthās está clara. É temerário afirmar que toda uma categoria de divindades, com funções e espaços proeminentes no panteão, deixe de ser reverenciada com bases estritamente ritualísticas. Esse tema, entretanto, é assunto de disputa no campo neste momento e envolve pesquisadores proeminentes como Hintze e Hultgård.
} 
exegética é muito clara. Vejamos então, mais uma vez, o verso 33: "Ēn-iz gōwēd kū: “Ēn zamīg an-abēsar ud a-nišēb ud hāmōn bē bawēd; ud kōf ud čagād, ud gabr, ud ul dārišn ud frōd dārišn nē bawēd”.

Em sua tradução para o inglês, Zeek Kassock procede da seguinte forma com o termo: "This too is said: "This earth will become without-height [uncrowned] and without-bottom [declivity] and level; there will be no mountains and peaks, hollows, and high land [up-holdings] and low land [down-holdings]." (KASSOCK, 2013, p. 408).

O termo em questão aparece literalmente traduzido entre colchetes, após o tradutor manifestar a ideia implícita na locução; igualmente também todas as outras locuções que se referem a acidentes geográficos. Assim, o que Lincoln considera um termo "chave" não passa de um recurso estilístico comum do persamédio, real motivo da adoção dessas formas para se referir a tais acidentes geográficos, e não de um recurso metafórico do autor da Bd. Acredito ser inegável que a Bd 34 esteja prevendo a unidade da humanidade sob o justo governo de Ohrmazd, entretanto o argumento de Lincoln, que dá ênfase ao fim das diferenças sociais entre os homens, baseado na expressão "sem-coroa”, me parece exagerado. Chamar os picos congelados das montanhas de coroas, a meu ver, nada mais é do que uma catacrese, comum a uma sociedade tão ligada a regimes monárquicos como a iraniana e reforçada pelo recorrente uso dessa figura de linguagem nas imagens literárias. O termo an-abēsar não significa ao mesmo tempo "sem-coras brancas" e "sem classes sociais". Refere-se apenas aos altos picos dos montes, que nessa região, quase sempre cobertos de neve, parecem estar usando coroas brancas. Portando, o texto persa-médio lê literalmente "sem-coras", mas o significado intendido é "sem montanhas” e não “sem coroas”.

Baseado nesses argumentos, seria muito mais plausível, no meu entender, ver o fim das montanhas na Bd como algo muito mais centrado na união de toda a humanidade, por meio do fim de diferenças culturais e étnicas, estas sim, divididas pelas montanhas, que na prática dividem com muito mais clareza etnias e línguas e 
não classes sociais. Além do mais, segundo o próprio texto da $\mathrm{Bd}$, a figura monárquica continua existindo na pessoa de Ohrmazd, o que torna problemática a declaração de Lincoln de que não haverá mais figura monárquica sobre a Terra. A permanência da monarquia divina, após o julgamento final, demonstra que o(s) autor (es) da Bd não tinha(m) problemas diretos com esse sistema de governo.

Ao analisar outra tradição textual, Lincoln admite que para esta o argumento do nivelamento das montanhas como símbolo para o fim das classes sociais simplesmente não se encaixa. Segundo ele próprio, nos Oráculos de Hystaspes o nivelamento das montanhas é apenas mais uma das desgraças que ocorreriam nos tempos do fim:

Verdadeiramente, estrelas irão repetidamente cair e o firmamento aparecerá escuro, sem nenhuma luz. Também, as maiores montanhas cairão, e serão aplainadas com as planícies, e o mar tornar-se-á inavegável [...] Ninguém respeitará os idosos, nem conhecerão as obrigações piedosas. Nem sexo (isto é, diferenciação entre masculino e feminino) nem crianças serão poupados. Tudo será confundido e misturado, contra 0 que é certo e contra as leis da natureza. (LACTÂNCIO, 1886, VII-16).

Para Lincoln, isso se deve à herança de pensamento que os Oráculos de Hystaspes têm em comum com o Zand i Wahman Yasht 4.35-37 ${ }^{17}$ onde a mistura de classes sociais é um sinal de desordem e influência demoníaca. Isso fica claro, segundo o autor, quando são associados, no mesmo trecho, a queda de estrelas, a falta de navegabilidade do mar e o nivelamento das montanhas com a confusão e a mistura de todos, bem como o desrespeito para com os idosos, a indistinção entre os gêneros e fases etárias, enfim, tudo estará confundido contra o que é certo e contra as leis da natureza. Parece que, para certo ramo do pensamento iraniano, que Lincoln considera inclusive ser o mais antigo, a divisão dos homens em classes sociais, idades e gêneros era uma pedra angular que demonstrava uma ordem natural das coisas, refletida pelo mundo social (LINCOLN, 1983, p. 147). Nesse sentido, a imagem de montanhas sendo desfeitas só poderia ser encarada como

\footnotetext{
17 “Os pedintes tomam as filhas dos nobres e poderosos e dos Magos em casamento, e os nobres e poderosos e os Magos vão à pobreza e servidão, enquanto os pedintes são levados à liderança e aos primeiros lugares. E o discurso dos portadores da boa religião, 0 selo e a decisão do justo juiz, o discurso dos justos e também dos retos tornou-se considerado meramente ralé, enquanto o discurso dos pedintes, dos caluniadores, dos perversos, dos escarnecedores e os dos mentirosos é visto como justo juízo e verdade".
} 
reflexo do caos apocalíptico e não como uma providência divina para o estabelecimento do reino eterno. Lincoln encaminha então o seguinte raciocínio:

Plutarch and the Bundahishn make the leveling of mountains the culminating act of the cosmic Renovation, while Lactantius groups it among the apocalyptic woes. What is more important, we have shown that this variation is not random, but perfectly parallels another variation between the two groups of texts, that relating to attitudes toward differences in social status. Thus, when social distinctions are negatively valued as interfering with the unity of mankind, the leveling of mountains appears as the greatest good. But when social distinctions are positively valued as necessary for the order of the universe, then the leveling of mountains is reduced to one woe among many. (LINCOLN, 1983, p. 148).

Sumarizando esta parte do argumento de Lincoln: o autor associa a adjetivação do derretimento das montanhas e do consequente aplainamento da Terra à ideia geral que uma suposta tradição textual dá às diferenças sociais. Haveriam textos nos quais as barreiras seriam algo bom e essencial ao mantenimento da ordem e, portanto, seu desaparecimento é listado apenas como mais uma das catástrofes apocalípticas. Outros textos, por sua vez, considerariam que as barreiras entre os homens não seriam a vontade inicial da divindade, não passando do resultado do ataque das forças malignas, como é o caso do próprio Bd 6:1-3 $3^{18}$. Assim, o evento seria o ápice da intervenção salvífica divina. Porém, em minha opinião, há algumas ressalvas a serem feitas nesta argumentação.

Em primeiro lugar, cabe crítica à contradição do autor quando ele nega que haja sentido específico em comparar o aplainamento da Terra judaico com o iraniano e, logo em seguida, estabelece relações com textos budistas, corânicos e, até mesmo, com um manifesto da guerra civil inglesa do século XVII. Em segundo lugar, pode-se levar em consideração as pesquisas e as opiniões de John R. Hinnelss e Hultgård, não só acerca do Oráculo de Hystaspes, mas de toda a tradição apocalíptica iraniana. Para Hinnelss, não há a diferença de tradições textuais apocalípticas entre o Zand i Wahman Yasht e a Bd:

\footnotetext{
${ }^{18} 6: 1$ "As the Evil Spirit scattered in and the Earth trembled, the essence of the mountains were created in the Earth; in the quaking of the Earth, immediately, mountains stood in motion: first, Harburz of Divine Providence, then the other mountains in the middle of the Earth; for, as Harburz grew forth, all mountains stood in motion; for all grew forth from the roots of Harburz; in that time, they went forth from the Earth, like trees, which cause the [its?] branches to move above, and the roots below, their roots, one into another, were arranged in connection. 2. And after that, it was not possible for the Earth to tremble in its place. 3. As it is said in the Religion: "The mountain is a great connection of the lands." Ver: Kassock (2013, Vl, 1-3).
} 
A significância deste argumento, como o de Benveniste, não é meramente que outro bloco de material em Lactâncio é adicionado ao oráculo de Hystaspes, mas muito mais que o oráculo é visto representando acuradamente a típica e tradicional - tanto em gênero quanto em espírito e detalhes - teologia apocalíptica zoroastrista tal qual esta é representada em obras como Zand i Wahman Yasht, Jamasp Namag, Bundahišn e Denkard. (HINNELSS, 1973, p. 136).

Aqui, vemos que para Hinnells a Bd é consonante com a tradição do Zand Wahman Yasht e do Jamasp Namag, o que vai diretamente ao encontro da argumentação de Lincoln. Hultgård, por sua vez, concorda que a inversão de valores e da ordem social é uma "proeminente marca maligna do fim dos tempos" para toda tradição zoroastrista como um todo (HULTGÅRD, 1999, p. 49).

Em terceiro lugar, é muito perigosa a asserção de Lincoln que diz: "For the most part, no specific significance can be posited for the use of this image in any of these sources, it being simply a stereotyped and rather bland image of catastrophe (LINCOLN, 1983, p. 149)”. E ele a faz principalmente ao se referir aos textos judaicos. $\mathrm{O}$ argumento de Lincoln me parece um disparate. Percebe-se, ao longo de seu artigo, que ele trabalha com fontes em persa-médio e em grego, por isso vai ao Apocalipse de João, mas, em nenhum momento, cita qualquer fonte em hebraico ou em ge'ez. Fica aparente que a desqualificação da imagem do aplainamento da Terra em fontes judaicas é fruto de certa insegurança do autor em relação a essas fontes e suas línguas originais. Em certo ponto, ele afirma, até mesmo, não ter interesse nelas por descrer de quaisquer perspectivas "universais" ou "arquetípicas", para depois, como já supracitado fazer paralelos com o Corão e textos budistas (LINCOLN, 1983, p. 148-149). É louvável o esforço de Lincoln para compreender uma imagem apocalíptica a partir de sua própria cultura e, ao mesmo tempo, estar atento para não cometer erros crassos que podem advir de uma tentativa desesperada de encontrar paralelos. Entretanto, continuo acreditando que com a devida cautela e pesquisa, pode-se fazer um trabalho que busque compreender os empréstimos e origens não só das imagens apocalípticas, mas também de outros aspectos entre povos de culturas diversas, como já demonstraram ser possível diversos autores como, por exemplo, Martin L. West. 
É por isso que, em seguida, investigarei alguns textos judaicos anteriores a 1En, em que a imagem das montanhas se desfazendo recorre, para perceber em quais contextos esses trechos se encontram. Posteriormente, analisarei a imagética das montanhas conforme aparecem em 1En. Em seguida farei o mesmo no capítulo 67 de 1En, no qual os paralelos com a Bd 34 se tornam evidentes.

\section{As montanhas se desfarão - fontes judaicas e 1 Enoque ${ }^{19}$}

Conforme dito anteriormente, o topos literário das montanhas que se desfarão aparece em várias culturas antigas. Analiso agora alguns casos de sua forma judaica. O assunto é especificamente de escassa bibliografia. Acredito que isto se dê pelo fato de que o desaparecimento das montanhas pode ser facilmente relegado a apenas uma bela metáfora. Os trechos de 1En em questão são os seguintes:

52:6. Aquelas montanhas que seus olhos viram - a montanhas de ferro, e a montanha de cobre, e a montanha de prata, e a montanha de ouro, e a montanha de metal macio, e a montanha de chumbo - Todas elas serão perante $\mathrm{O}$ Ungido como cera perante o fogo, e como água que desce do topo das montanhas, e serão enfraquecidas perante seus pés. (1 $\mathrm{ENOCH}$, 2012, p. 1106).

53:7. E essas montanhas serão na presença do justo Ungido como cera e as Colinas serão como uma fonte de água [...] E eles trarão os reis e os poderosos e os jogarão neste profundo vale. (1 ENOCH, 2012, p. 1126).

67:7. E através dos vales daquele lugar rios de fogo irromperão, onde aqueles anjos serão julgados, aqueles que desviaram os que habitam a Terra. (1 ENOCH, 2012, p. 1396).

Nestes versos, e em seus contextos, aqui não acrescentados por uma questão de espaço, vemos cenas de juízo divino associados ao derretimento das montanhas e os respectivos metais contidos nelas. É por esta razão que creio ser necessário uma análise mais cuidadosa do que as montanhas significavam em textos judaicos já bem estabelecidos à época de cristalização da tradição enóquica o que nos leva para o Tanakh.

\footnotetext{
${ }^{19}$ Todas as citações bíblicas nessa seção são versões portuguesas a partir do softwer exegético: King James Version with Strong Numbers. In: Bible $+^{\mathrm{TM}}$ for Windows Desktop. Product Version: 5.4.1. Todas as citações de 1En são versões portuguesas retiradas de 1Enoque: the Hermeneia translation (2012) cotejadas com a transcrição do ge'ez original ("1 Enoque" in Ge 'ez (Ethiopian). Transliterado por DILLMANN, August. Edited by Michal Jerabek, Institute of Ancient Near Eastern Studies Charles University). A bem da justiça é necessário agradecer aqui ao professor Mathias Henze pelos essenciais apontamentos feitos para esta seção.
} 
Quando se inicia uma pesquisa acerca do que representam as montanhas ao longo dos textos judaicos, se encontra a primeira semelhança com o caso zoroastrista: a existência de uma mudança drástica acerca do valor qualitativo imbuído a esses acidentes geográficos. A mesma dubiedade que se manifesta no zoroastrismo entre os textos mais antigos e os mais recentes se apresenta com relação ao Pentateuco e textos judaicos posteriores.

De acordo com Richard J. Clifford, as oitos principais montanhas que figuram no Pentatêuco -Ararate, Ebal, Gerezin, Horé, Moriá, Nebo, Seir e Sinai são sempre pintadas com a imagética de Templo (CLIFFORD, 2010, p. 34). Elas são palco de eventos sagrados importantíssimos, como o aportar da Arca salvífica (Gn 8:4) ou próprio recebimento da Lei (Ex 24:16). Pode-se verificar ainda a presença de uma forte noção, compartilhada ao longo do Oriente Próximo, de que alguns desses montes são o centro do cosmo, espécie de fundamento do mundo, como pode ser visto no paralelo entre Dt 32:22 ${ }^{20}$ e Gilgamesh IX-X (WALTON, 2006, p. 173).

Dentre outros motivos compartilhados com as ideias gerais do Oriente Próximo antigo acerca das montanhas ainda pode se citar: serem as moradas de divindades, locais de sacrifícios, de orações e de adoração, além de serem o próprio sustentáculo que mantém os céus acima da Terra (GEORGE, 1993, p. 70). Por sua própria estrutura, as montanhas são o lugar mais próximo dos céus e, por isso, naturalmente eram vistas como fazendo essa mediação entre o que estava em nível humano e o que estaria em nível divino.

Entretanto, quando deixamos o Pentateuco e passamos a outros escritos da tradição judaica, começamos a perceber que as montanhas deixam de ter tratamento tão sacralizado e começam a servir à imagéticas mais diversas na literatura hebraica. A meu ver, a imagem do desaparecimento das montanhas se presta a dois objetivos básicos e distintos: 1 . em textos de outras matrizes que não a

\footnotetext{
${ }^{20}$ Dt 32:22 "Sim! O fogo da minha ira está ardendo e vai queimar até o mais fundo do Sheol; vai devorar a terra e seus produtos, e abrasar o alicerce das montanhas" (King James Version).
} 
apocalíptica, ela concerne às expressões do poder divino e poderia ou não ser encarada como uma possibilidade literal; 2. em textos de matriz messiânica e/ou apocalíptica, se percebe a anunciação de uma nova era, por meio de um grande abalo na natureza.

Em oposição a essas imagens supracitadas temos a figura dos montes eternos. Não sabemos ainda se se deve considerar como contraditórias a tradição textual judaica que trata os montes como eternos e a que afirma que eles se desfarão. Talvez essa diferença possa ser devida justamente à influência iraniana. Fato é que, ao pensarmos os paralelos entre judaísmo do Segundo Templo e zoroastrismo, temos de ter em mente vários textos ${ }^{21}$, como Salmo 125:1,2 que é difícil de ser ignorado: "1.Os que confiam no Senhor são como o monte Sião: nunca se abala, está firme para sempre. 2. Como em volta de Jerusalém estão os montes, assim é o Senhor em volta do seu povo desde agora e para sempre”. É interessante notar que o impasse só aumenta se considerarmos o nome próprio do monte em

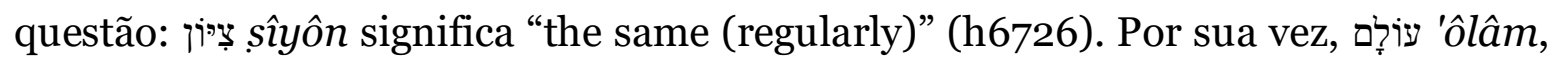
palavra hebraica para "properly, concealed, isto é, the vanishing point; generally, time out of mind (past or future), isto é, (practically) eternity (h6726)" aparece no final de ambos os versos. Diante de tal análise exegética, temos de lidar com a veemência do salmista ao declarar a eternidade do monte Sião bem como das demais montanhas que circundam Jerusalém.

Entretanto, são muitas as passagens que apresentam a figura dos montes se desfazendo. No livro dos Juízes, encontramos na canção de Débora um bom exemplo dessa imagem sendo utilizada com vistas de anunciar o poder de Javé. A King James traduz Juízes 5:5 da seguinte maneira: "As montanhas derreteram diante do Senhor, até mesmo o Sinai diante do Senhor Deus de Israel”. De acordo com o dicionário levado a cabo pela equipe da Drew University sob a liderança de James Strong, a palavra hebraica usada aqui é " n̦̣̂tzal; a primitive root; to drip, or shed by trickling:- distil, drop, flood, (cause to) flow (- ing), gush out, melt, pour (down), running water, stream (h5140)". Por estar inserida no contexto de um

\footnotetext{
${ }^{21} \mathrm{Gn}$ 49:26 e Hb 3:6 são outros exemplos em que montanhas e outeiros são adjetivados com a expressão hebraica 'ôlâm.
} 
hino de louvor a Javé, a imagem serve ao propósito de mensurar o poder da divindade: as montanhas, obstáculos praticamente intransponíveis aos homens da época, derreteriam diante da face do Deus de Israel. A imagem estabelece um padrão comparativo muito prático e de fácil entendimento para o ouvinte/leitor: a de que as rochas, intransponíveis para o ser humano, são como cera ou o metal diante da divindade, Ele pode derretê-las, assim como o homem faz com esses dois materiais. No entanto, pelo contexto geral da canção de Débora, é possível constatar que esse derreter dos montes não ocasiona nenhum evento futuro que possa estar conectado a ele, sua característica é essencialmente poética lembrando sempre que isto não significa, de forma alguma, que o escritor não cresse na possibilidade de isto de fato vir a ocorrer.

No livro dos Salmos, podemos constatar que havia entre os judeus a utilização das montanhas em construtos poéticos metafóricos, o que concorre para reforçar a ideia de que não devemos entender toda e qualquer citação de eventos estranhos ocorrendo com as montanhas como sendo literais para os religiosos da época. Sabe-se que a poesia hebraica era muito rica e capaz de se utilizar de imagens profundas e metafóricas (COOGAN; METZGER, 1993). O capítulo 104, por exemplo, cita que, quando Israel foi tirado pela intervenção divina do Egito, as montanhas "saltaram como carneiros e os outeiros como cordeiros". Por tratar-se de um texto em louvor a um feito passado, fica clara a alusão poética do autor, já que nenhum trecho do Êxodo trata de montanhas saltando de alegria na ocasião da libertação do povo de Israel, o que não exclui obviamente outras narrativas miraculosas. Em Isaías 55:12 ${ }^{22}$, encontramos as montanhas cantando perante Deus ao mesmo tempo que as árvores batem palmas, em mais uma demonstração de como a figura das montanhas era utilizada poeticamente pelos judeus. É necessário frisar que tal utilização ocorre de maneira semelhante também em 1En 51:4: "Naqueles dias as montanhas saltarão como carneiros, e as colinas saltarão como cordeiros satisfeitos com leite; e a face dos anjos no paraíso estará radiante de

\footnotetext{
${ }^{22}$ Is 55:12 "Haveis de sair com alegria e em paz sereis reconduzidos. Na vossa presença montes e outeiros romperão em canto, e todas as árvores do campo baterão palmas." (King James Version).
} 
alegria”. Deve-se, então, manter a mesma vigilância de análise tanto em 1En, quanto no Tanakh em geral.

Entretanto, no capítulo 2:1,2 de Isaías, encontramos eco das ideias pentatéuticas acerca das montanhas: "1.Visão que teve Isaías, fillho de Amós, a respeito de Judá e de Jerusalém. 2. Dias virão que o monte da casa do Senhor será estabelecido no mais alto das montanhas e se alçará acima de todos os outeiros. A ele acorrerão todas as nações [...]”. Vê-se que Javé tem sua própria montanha e que ela será estabelecida acima de todas as outras. Contudo, já se pode notar uma nova tendência com relação à imagem das montanhas: os verbos estão no incompleto, ou seja, as mudanças são esperadas para o futuro e dizem respeito a uma época em que eventos nunca ocorridos antes se darão. Abre-se a perspectiva profética na qual as mudanças concernentes às montanhas e colinas não só demonstram poeticamente o poder do Deus de Israel, mas também se tornam sinais miraculosos a serem aguardados para o futuro profético ou escatológico.

Em Isaías 34:3, encontramos novamente o derretimento das montanhas, dessa vez, porém, associado ao resultado da fúria de Javé: “Os seus mortos são lançados fora, o mau cheiro dos seus cadáveres se espalha, os montes derreterão com seu sangue". Aqui a palavra utilizada para "derreterão" é "ọָ mâsas; a primitive root; to liquefy; figuratively, to waste (with disease), to faint (with fatigue, fear or grief):- discourage, faint, be loosed, melt (away), refuse, utterly" (h4549).

Nesse caso, o autor usa o recurso imagético do derretimento das montanhas para expressar a quantidade de sangue que será derramada naquele fatídico dia. Por grandes matanças ocasionadas por batalhas não serem eventos raros no Oriente Próximo Antigo, é plausível crer que o autor conhecia o fato de que mesmo uma imensa quantidade de sangue não poderia derreter uma montanha, ou mesmo, uma colina. Restam, a meu ver, duas opções difíceis de dirimir entre si. Em primeiro lugar, se pode pensar que a batalha conduzida pelo Deus de Israel naquele dia, por ser claramente sobrenatural, poderia dar cabo desse efeito, também sobrenatural. Em segundo lugar, estamos diante de um fator complicador da 
análise, pois se encontraria concomitantemente no mesmo livro a utilização poético-metafórica e a esperança escatológica. De qualquer forma, pode ser evocada a ideia, hoje amplamente aceita, de que o livro do profeta Isaías seja um construto de duas ou mesmo três partes compostas por autores diferentes em períodos diferentes. Há, no entanto, trechos mais claros nesse sentido, dos quais podemos lançar mão para entendermos o simbolismo do aplainamento da Terra entre os judeus.

É o caso de Is 54:10: “Os montes se afastarão e os outeiros serão removidos; mas a minha benignidade não se apartará de ti, nem o pacto da minha paz será removido, diz o Senhor que tem misericórdia de ti”. Aqui temos para "depart” o original

מוּ whether intransitive or transitive):- cease, depart, go back, remove, take away" e para "removed" vis môt (h4131) "a primitive root; to waver; by implication, to slip, shake, fall:- be carried, cast, be out of course, be fallen in decay, exceedingly, fall (- ing down), be (re-) moved, be ready, shake, slide, slip". (Bible ${ }^{\mathrm{TM}}$ for windows desktop. Product version: 5.4.1 localização h4185).

O termo mûš volta a aparecer, desta vez conjugado a uma negação, para garantir que as bondades de Javé, bem como sua aliança, não serão removidas de sobre Israel. O interessante é que o elemento de comparação escolhido para dar certeza ao leitor/ouvinte são as montanhas e as colinas: elas serão removidas, mas a aliança do Deus de Israel não. Alguém poderia interpretar esse trecho dizendo que o autor compara a retirada da aliança de Javé com Israel à remoção das montanhas de seus devidos lugares, ou seja, algo impossível de acontecer. Entretanto, essa interpretação não levaria em consideração os outros trechos, inclusive do mesmo livro, onde o nivelamento dos montes não está associado a uma impossibilidade. Ao levar em consideração o corpus documental, temos de interpretar essa passagem como sendo uma afirmação de que, mesmo quando os grandes prodígios escatológicos ocorrerem, o pacto de Javé permanecerá firme.

Os profetas menores também contêm diversos trechos concernentes a montanhas. Um desses trechos inicialmente não diz respeito ao nosso objeto, mas 
como se pretende analisar o simbolismo de certa imagem, é preciso passar por todos os tipos de ocorrências sobrenaturais em montanhas. Em Joel 3:17,18, há novamente a referência ao monte Sião como lugar de habitação de Javé, porém, no v.18, uma imagem diferente é associada às montanhas:

17. Assim sabereis que eu sou o Senhor vosso Deus, morando em Sião, o meu santo Monte; então Jerusalém será santa, e não passarão mais estranhos por ela. $18 \mathrm{E}$ acontecerá naquele dia que os montes gotejarão vinho novo, e dos outeiros escorrerá leite, e todos os rios de Judá fluirão com águas, e uma fonte sairá da casa do Senhor, e regarão o vale de Sitim. (Joel 3:17,18).

As montanhas passariam a gotejar vinho novo, das colinas escorreria leite e da casa de Deus viria uma torrente de água23. A situação trata, mais uma vez, de uma profecia para um futuro no qual as montanhas e colinas estão associadas a um contexto de benção inimaginável, imagens de fertilidade sobrenatural são associadas aos acidentes geográficos. Entretanto, não há nenhuma menção de seu desaparecimento, conforme podemos ver por meio de análise exegética. O termo para “shall drop" é nậtap (h5197) uma raiz primitiva para "to ooze, i. e. distil gradually; by implication, to fall in drops; figuratively, to speak by inspiration:drop (- ping), prophesy (- et)” o que não nos dá nenhuma indicação de que a montanha possa vir a se desfazer. Esse nâtap é uma onomatopeia muito parecida com o ge'ez, natabțāb (LESLAU, 1991, p. 587), que indica o gotejar natural das estalagmites e estalactites, estas que por sua vez não são capazes de esgotar uma

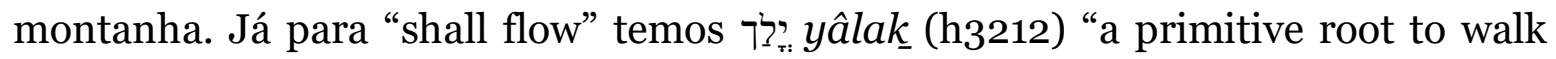
(literally or figuratively); causatively, to carry (in various senses)”, o que, da mesma forma, não denota nenhuma imagem de esvaziamento completo a ponto de as colinas se desfazerem. Sendo assim, temos ainda essa terceira possibilidade, que é a de montanhas e colinas serem inesgotáveis fontes de alimento após um livramento sobrenatural que Javé daria aos filhos de Israel.

\footnotetext{
${ }^{23}$ Uma imagem semelhante pode ser encontrada em Ezequiel 47:1: “Depois me levou de volta à porta da casa; E eis que saíam águas debaixo do limiar da casa, para o oriente; porque a frente da casa estava para o oriente, e as águas desciam do lado direito da casa, ao lado sul do altar". (King James Version).
} 
Em Naum 1:5, encontramos o trecho de um hino ao poder de Javé em que o abalo das montanhas acontece por conta de terremotos e o derretimento das colinas, mediante a presença da divindade: "As montanhas tremem diante dele, e os outeiros se derretem, e a terra é queimada ante sua presença, sim, o mundo e todos os que nele habitam". O termo original para "melt" é מוּג mûg (h4127) "a primitive root; to melt, isto é, literally (to soften, flow down, disappear), or figuratively (to fear, faint): consume, dissolve, (be) faint (- hearted), melt (away), make soft”, expressão semelhante usada em outros casos analisados, carrega o sentido de que as colinas desaparecerão depois de derreter. As montanhas, apesar não estarem diretamente associadas a um verbo de derretimento no caso, sofrerão

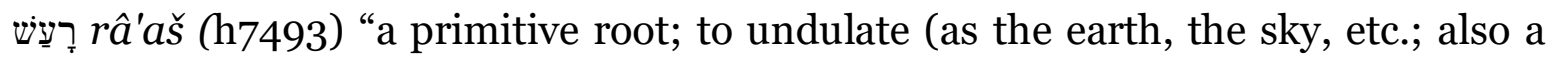
field of grain), partic. through fear; specifically, to spring (as a locust): - make afraid, (re-) move, quake, (make to) shake, (make to) tremble” ou seja, um poderoso abalo, mas não se pode inferir que tenham sido eliminadas.

Esse caso é parecido ao de Juízes, por se tratar de um hino ao poder de Deus e mais uma vez permanece a dificuldade em determinar se o autor aguarda uma literalidade futura para o evento ou se ele apenas crê hipoteticamente que Deus possa realizar esse feito. Sendo como for, esse trecho é importante pois traz consigo uma semelhança importante com 1En 67 e consequentemente com Bd 34: a presença da divindade faz com que as colinas se derretam.

No livro do profeta Amós, por sua vez, encontramos a soma da imagem encontrada em Joel com a do derretimento, formando, assim, um importante trecho para essa pesquisa, superado apenas pelo de Is 40:3-5;10 que será analisado em seguida. O trecho em questão é Amós 9:13: "Eis que virão dias, diz o Senhor, em que aquele que semeia estará próximo daquele que colhe, aquele que pisa as uvas daquele que plantou a semente; e as montanhas destilarão mosto e todas as colinas derreter-se-ão”. Aqui nós temos especificidades tanto do texto de Joel quanto do de Naum combinadas. 
De Joel, temos as montanhas que gotejam/destilam mosto, inclusive com a utilização da mesma palavra nâtap, enquanto que, de Naum, temos a preservação das montanhas, ou ausência da menção de sua destruição conjugada ao derretimento das colinas, em que a mesma raiz primitiva mûg é aplicada. O contexto é, mais uma vez, de profecia para um futuro glorioso, no qual o Deus de Israel restauraria o tabernáculo de Davi, conforme sua antiga glória e, no final do capítulo, temos a promessa de que Javé plantaria o seu povo naquela terra e de lá eles nunca mais seriam arrancados. Novamente encontramos o derretimento dos outeiros associado aos eventos futuros que passam por influência direta da divindade.

Agora parto para a análise do trecho que, depois de 1En 67, é o que mais encontra paralelos com o da Bd 34 em relação à questão dos montes: Is 40:3-5;10. Vejamos o trecho da profecia:

3-5 A voz do que clama no deserto: Preparai o caminho do Senhor, endireitai no deserto um caminho para o nosso Deus. Todo vale será exaltado, e todo o monte e outeiro será reduzido; e os tortuosos serão endireitados, e os lugares escarpados se tornarão planos. E a glória do Senhor será revelada, e toda a carne a verá junta; Boca do Senhor falou [..] 10. Eis que o Senhor Deus virá com mão forte, e seu braço governará para ele; eis que o seu galardão é com ele, e a sua obra diante dele. (Is 40:3$5 ; 10)$.

Incialmente cinco motivos em comum podem ser listados: 1) Em primeiro lugar, trata-se de uma chamada à preparação da intervenção divina, a ideia de nivelamento já é anunciada e ao misterioso personagem que clama no deserto é dada a função de criar uma ợ mesilâ (h4546), uma estrada plana no deserto; 2) Em segundo lugar, pode-se notar a semelhança na constatação de que os vales serão elevados, o que faz do evento de aplainamento da Terra um processo equânime, garantido pelo fato de que não só as montanhas serão desfeitas, mas locais muito baixos também serão exaltados; 3) Terceiro: o evento do aplainamento da Terra é o último milagre antes da glória da divindade ser revelada, então, o

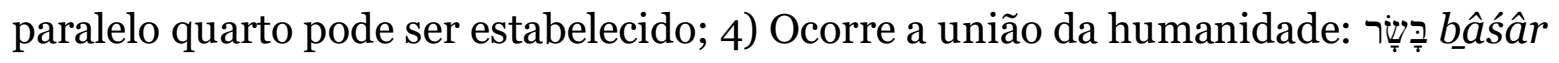
(h1320), palavra comumente usada em hebraico para referir-se a seres humanos e 
יִ yahad (h3162) arremata com a ideia de unidade; 5) Finalmente, reunida a humanidade, o próprio Deus pode reinar entre os homens.

A comparação destes trechos, se considerando a comuno opinio acadêmica acerca do intercâmbio cultural entre judeus e persas-zoroastristas, é de grande importância para a compreensão dessa imagética apocalíptica. Pode-se perceber, no texto de Isaías, que as montanhas e acidentes geográficos em geral, como os vales e lugares escabrosos, são considerados símbolos da desunião humana. Obviamente não são tratados como únicos culpados pela desunião, mas, por se colocarem tantas vezes como obstáculos à movimentação do homem antigo, passaram a simbolizar o impedimento do contato com outras culturas e etnias. É possível perceber aqui também que a união da humanidade é motivo principal do aplainamento da Terra e nenhuma menção a conflitos de classes sociais está presente no capítulo. Entretanto, assim como na análise da Bd 34, não estou afirmando que um contexto político não está presente, pois, conforme o paralelo 5, o reino passa à mão da própria divindade, o que pode levar ao entendimento de que não há mais nobres.

Aproximando-nos de 1En em si, veremos ocorrências de Montanhas no "Livro dos Vigilantes" e no "Livro das Parábolas". A escolha do "Livro dos Vigilantes" se dá pelo fato de que ele fora o primeiro material enóquico escrito e, por isso, se tornou matriz para todos os outros. Já a escolha das "Parábolas" se dá por ser o Livro de 1En que carrega material central para este artigo: o capítulo 67.

Nickelsburg entende o significado da imagética das montanhas da seguinte maneira:

O metal das montanhas, ademais, representa as riquezas dos poderosos (ouro e prata) e os materiais empregados nas armas de guerra (ferro, bronze, estanho e chumbo). Isto é, o julgamento põe um fim à opressão das riquezas e da violência militar dos poderosos. O agente do julgamento é o Ungido de Deus e Escolhido e isto está em consonância com a ênfase das "Parábolas", amarrando essa seção ao contexto. (NICKELSBURG, 2007, p. 32). 
Para Nickeslburg, as seis montanhas de 52:1-9 correspondem, de certa forma, às sete montanhas em 18:6-9 e 24:2-4, sendo a sétima a "montanha de Deus". Porém, já se pôde perceber que as montanhas do "Livro dos Vigilantes" são bem diferentes das do "Livro das Parábolas", sendo compostas de pedras preciosas enquanto as outras são de metais (NICKELSBURG , 2007, p. 32). Além disto, parece estar bem indicado pelo contexto geral do "Livro dos Vigilantes" que o derretimento dos metais está associado ao fim de sua utilização para mantenimento do poder dos opressores. No caso, o derretimento dos metais menos nobres, utilizados para fins bélicos, simbolizaria o fim das guerras enquanto que o dos metais mais nobres, utilizados para fins financeiros, simbolizaria o fim da opressão monetária.

No "Livro das Parábolas", o(s) autor (es) traz/trazem as montanhas de volta à cena, entretanto, o destaque naquilo que o derretimento dos metais nelas contido pode resultar - fim das opressões militares e monetárias - e transferido para o fenômeno do derretimento em si, com ênfase no caráter sobrenatural do poder divino em operá-lo. De acordo com Knibb,

A alusão no cap. 52 a montanhas de metal no Oeste, que servirão à autoridade do messias de Deus (v. 4) e irão derreter como cera perante O Escolhido (v.6) parece ter sido influenciada pela tradição de sete montanhas preciosas no Nordeste $\left(18: 6-9^{\mathrm{a}} ; 24: 1-3 ; 25: 1-3\right)$, montanha central está coincide com o trono no qual Deus se assentará quando vier visitar a terra. Entretanto, essa tradição foi transformada por associação com outra familiar, a das passagens teofânicas em que as montanhas se derretem perante a vinda de Deus (Mq. 1:4; Sl 97:5; Na 1:5; Jz 5:4). Seria ainda transformada pela sua combinação com o tema dos metais, que é visto sem dúvida, como em Dn 2:31-45, como representativo de uma sucessão de impérios mundiais". (KNIBB, 2007, p. 56).

As conclusões de Knibb são muito importantes para esta seção, pois apontam para a possibilidade de que o tema das montanhas fora transformado, por associação com outros temas familiares, como o tema dos metais na sucessão de impérios mundiais. Destarte, quando chegamos a 1En 67, encontramos de novo as montanhas do Oeste, desta vez, porém, associadas à formação de um vale que irrompe em rios de metal incandescente, um local apropriado para a realização de um rito de justiça divina. 
De tal modo, é perceptível que as montanhas em 1En aparecem como um grande amálgama de motivos presentes na literatura judaica que o antecede. Os especialistas supracitados apontam para significados diversos relativos às montanhas que, provavelmente, foram construídos sobre aspectos existentes em textos anteriores a 1En como o derretimento e fruição de seus elementos internos.

\section{Conclusões: Por que as Montanhas devem desaparecer?}

Ao analisarmos o fim das montanhas na $\mathrm{Bd} 34$, é inegável que o texto esteja tratando da esperança de um futuro escatológico quando nada mais será como antes. Fica claro também que o papel do nivelamento dos montes e picos, bem como das depressões, tem um papel importantíssimo na reforma de uma paisagem que representava os empecilhos para o contato entre os mais diferentes povos, aliás, não parece exagero dizer que, para a cosmovisão presente na $\mathrm{Bd}$, foram essas dificuldades impostas pelas montanhas que acabaram por gerar as diferenças entre os povos. Entretanto a interpretação de Lincoln supervaloriza o fim das classes sociais quando esse fator, para a lógica interna do texto, parece ser apenas uma consequência decorrente do que realmente importa: o fim das diferenças étnicas e linguísticas e principalmente religiosas entre os povos. Faz-se necessário acrescentar que ler zoroastristas antigos como apoiadores da pluralidade religiosa é um anacronismo crasso e a unidade religiosa esperada para humanidade, no caso da Bd, é obviamente que ela seja por completo Masdeísta.

É de igual forma importante citar a questão da literalidade dessas profecias para os fiéis da época. A tendência de metaforizar esses elementos é carregada de valores posteriores retroalimentados sobre o texto na tentativa de torná-los “aproveitáveis" ou "plausíveis" diante de uma sociedade contemporânea. No caso de Lincoln, o que se percebe é uma insistência em encontrar temas de resistência e combatividade sociais nos textos apocalípticos. Tal tendência, muito famosa na década de 1980, proporcionou grandes avanços no entendimento da literatura apocalíptica, no entanto, quando exacerbada, pode se tornar uma lente de distorção anacrônica. Nunca podemos deixar de nos lembrar de que para um zoroastrista da 
época em que a Bd foi escrita, as montanhas eram de fato resultado do assalto de Ahriman à planicidade natural da criação de Ohrmazd, sendo assim, para que os povos se unissem, seria necessário o fim factual dessas barreiras. Isto é deveras diferente de uma possível união social mediante tomada de consciência perante uma pretensa lição metafórica. Obviamente outros elementos se fazem presentes ao longo do capítulo e do texto, tais como a purificação dos pecados pelo rio de metal incandescente e o reinado do próprio Ohrmazd, o que, na minha opinião, só contribui para a necessidade da interpretação literal do fim das montanhas.

No atual estágio desta pesquisa, se conclui não ser possível atribuir o fim das montanhas no judaísmo exclusivamente a um empréstimo zoroastrista, entretanto a associação do derretimento metálico é uma imagem muito comum no contexto zoroastrista. A combinação final desses motivos aconteceria especificamente em 1En 67. Contudo é necessária atenção ao baixo número de trechos zoroastristas acerca do fim das montanhas se comparado ao número que temos entre os trechos judaicos. Se o aplainamento da Terra pelo fim das montanhas e elevação dos vales é de fato uma influência iraniana entre os judeus, poderíamos dizer que estes, mediante as fontes das quais dispomos hoje, fizeram muito mais uso dessa impressionante imagem apocalíptica do que teriam feito seus originais criadores.

Depois de percorrermos diversos textos do Tanakh que citam o derretimento das montanhas, podemos concluir que o elemento sincretizado à imagética judaica pelo fator zoroastrista seja especificamente a presença do metal incandescente. Com exceção de 1En, não há nenhuma ocorrência da questão metálica diretamente associada ao derretimento das montanhas e colinas, seja nos livros narrativos, poéticos ou proféticos do Tanakh. Somente o livro de Ezequiel traz menção de julgamento associado ao uso de fundição ${ }^{24}$, entretanto os metais citados não são provenientes de montanhas ou colinas e toda a figura de juízo se passa num ambiente de forja. Porém, ainda mais importante é que a perícope de Ezequiel não

\footnotetext{
${ }^{24}$ Capítulo 22:18-21: "Filho do homem, a casa de Israel se tornou escória para mim; são todos escória de cobre, estanho, ferro e chumbo em uma fornalha. Com efeito, assim diz o Senhor Javé: 'Pois que todos vós vos tornastes escória, eis que vou reunir-vos no meio de Jerusalém. Como reúnem prata, cobre, ferro, chumbo e estanho em uma fornalha, para atiçar fogo sobre eles, a fim de fundilos, assim vos reunirei na minha ira e na minha cólera e vos farei fundir. Juntar-vos-ei e soprarei sobre vós o fogo da indignação, fundindo-vos no meio da cidade'."
} 
trata de um futuro escatológico universal, mas de um julgamento específico para os infiéis da casa de Israel.

Ao que parece, para Nickelsburg e Knibb, as montanhas de 1En, tanto reverberam motivos presentes nos escritos proféticos, quanto estão “abertas” a receber outros significados emprestados de tradições próximas já inseridas no pano de fundo da tradição. A ideia pode ser vista da seguinte forma: os oráculos de Deus profetizaram que as montanhas derreterão em sua presença, daí caberia especular: no que esse derretimento acarreta? A resposta, segundo o "Livro das Parábolas", seria esta: as montanhas derreteriam para dar vazão ao local onde poderes opressores, tanto sobrenaturais quanto humanos, encontrassem sua justa punição. O motivo da justiça divina permanece em ambas as seções de 1En, mas com alguma diferença. No primeiro, se destrói o meio da opressão e, no segundo, o opressor em si. Nos dois, entretanto, se encontra a mais direta intervenção divina e de maneira alguma a ação de determinado grupo social.

Conclui-se então, até o presente momento, que uma possível influência zoroastrista no texto de $1 \mathrm{En} 67$ poderia ser a questão do metal incandescente. $\mathrm{O}$ desaparecimento das montanhas e dos outeiros tem, em ambas as literaturas, uma relação muito próxima com o anúncio ou com a consequência de uma intervenção divina fulcral e, por isso, em quase todos os textos em que aparece, tem a função de arrematar uma profecia.

A questão de a união da humanidade ser propiciada pelo desaparecimento das barreiras naturais, que aparece com clareza na $\mathrm{Bd}$, não parece tão clara nos textos judaicos, porém, dias de benção perene e reinado messiânico estão associados ao aplainamento da Terra. Portanto, pode-se interpretar essa imagem apocalíptica como uma esperança, um anseio por um mundo totalmente novo, sem barreiras entre os povos, regido pela justiça da própria divindade, cujos poucos outeiros que restassem existissem não para separar, mas apenas para destilar mosto e leite. 


\section{REFERÊNCIAS}

1 ENOCH: the Hermeneia translation. Translation by George W. E. Nickelsburg and James C. Vanderkan. Minneapolis: Fortress Press, 2012.

1 ENOQUE IN GE`EZ (ETHIOPIAN). Translation by August Dillmann. In: JERABEK, Michal. (Ed.). Institute of ancient near Eastern studies Charles University - Prague - Czech Republic. Disponível em:

<http://www.ic.unicamp.br/ stolfi/voynich/Notes/103/work/Notes/111/work/TextsOld/ geez/eno/main.org>. Accesso em: 10 dez. 2013.

AVESTA. The hymns of zoroaster: a new translation of the most ancient sacred texts of Iran). Translation by Martin L. West. New York: I.B. Tauris, 2010.

BOYCE, Mary. Textual sources of the study of zoroastrianism. Chicago: University of Chicago Press, 1990.

CERETI, G. Carlo. Myths, legends, eschatologies. In: Stauberg, MICHAEL; VEVAINA, Yuhan Sohrab-Dinshaw (Ed.). The Wiley-Blackwell companion to zoroastrianism. Oxford: Wiley Blackwell, 2015.

CHARLESWORTH, James H. (Ed.). The Old Testament pseudepigrapha apocalyptic literature \& testaments. Yale: University Press, 2013.

CLIFFORD, Richard J. The cosmic mountain in Canaan and the Old Testament. Cambridge: Harvard University Press, 2010.

COOGAN, MICHAEL D.; BRUCE METZGER. Psalms. In: The Oxford companion to the Bible. Oxford: Oxford University Press, 1993.

GEORGE, A. R. House most high: the temples of ancient Mesopotamia. Winona Lake: Eisenbrauns, 1993.

HERÓDOTO. As guerras pérsicas. Volume I: livros 1-2. Tradução A. D. Godley. Cambridge: Harvard University Press, 1911.

HINNELLS, John R. The Zoroastrian doctrine of salvation in the Roman world. In: SHARPE; HINNELLS. Man and his salvation: studies in memory of S. G. F. Brandon. Londres: Manchester University Press, 1973. cap.11, p.125-148.

HINTZE, Almut. Monotheism the Zoroastrian way. Journal of Royal Asiatic Society, Cambridge, v. 24, n. 2, p. 225-249, abr. 2014.

HULTGÅRD, Anders. Persian apocalypticism. In: COLLINS, John; MCGINN, Bernard; STEIN, Stephen (Ed.). The enciclopedia of apocalypticism: vol. 1: the origins of apocalypticism in Judaism and Christianism. New York: The Continuum, 1999. 
KASSOCK, Zeke J. V. The greater Iranian Bundahishn: a Pahlavi student's 2013 guide. Scotts Valley: CreateSpace Independent Publishing Platform, 2013.

KNIBB, Michael A. The structure and composition of the parables of Enoch. In: BOCCACCINI, Gabriele (Ed.). Enoch and the messiah son of man: revisiting the book of parables. Grand Rapids: William B. Eerdmans Publishing Company, 2007.

LACTÂNCIO, Lucio Célio Firmiano. Instituições divinas. Tradução William Fletcher Buffalo. Nova York: Christian Literature Publishing Company, 1886.

LESLAU, Wolf. Comparative dictionary of ge'ez. Wiesbaden: Harrassowitz, 1991. p. 587.

LINCOLN, Bruce. The earth becomes flat - a study of apocalyptic imagery. Comparative Studies in Society and History, Cambridge, v. 25, n. 1, p. 136-153, jan. 1983.

MACKENZIE, David Neil. A concise Pahlavi dictionary. Oxford: Oxford University Press, 1986.

NICKELSBURG, George W. E. Discerning the structure(s) of the Enochic book of parables. In: BOCCACCINI, Gabriele (Ed.). Enoch and the messiah son of man: revisiting the book of parables. Grand Rapids: William B. Eerdmans Publishing Company, 2007.

PIOVANELLI, Pierluigi. A testimony for the kings and the mighty who possess the earth. In: BOCCACCINI, Gabriele (Ed.). Enoch and the messiah son of man: revisiting the book of parables. Grand Rapids: William B. Eerdmans Publishing Company, 2007.

PLUTARCO. Morália (Ísis e Osíris). Tradução Frank Cole Babbitt. Cambridge: Harvard University Press, 1911.

SKJÆRVØ, Prods Oktor. Introduction to Zoroastrianism. Iranian studies at Harvard University, 2006. Disponível em: <http://www.fas.harvard.edu/ iranian/> Acesso em: 16 jun. 2018.

SKJÆRVØ, Prods Oktor. The Videvdad: its ritual-mythical significance. In: CURTIS, Vesta Sarkhosh; STEWART, Sarah (Ed.). The age of the parthians. The Idea of Iran 2, London, v. 2, p. 105-41, 2007.

SUNDERMANN, W. Bahman yasht. In: YARSHATER, Ehsan. Encyclopaedia iranica, Fasc. 5, 1988. p. 492-493. v. III.

THE HOLY BIBLE. King James version with strong numbers. Bible+TM for windows desktop. Product version: 5.4.1

WALTON, John H. ancient near eastern thought and the Old Testament: introducing the conceptual world of the Hebrew Bible. Grand Rapids: Baker Academic, 2006. 